\title{
The effects of policy design complexity on public support for climate policy
}

\author{
Lukas Paul Fesenfeld \\ ETH Zurich/University of Bern, Bern, Switzerland \\ E-mail: lukas.fesenfeld@gess.ethz.ch; lukas.fesenfeld@ipw.unibe.ch
}

(Received 4 January 2021; revised 2 December 2021; accepted 18 January 2022)

\begin{abstract}
Important challenges like climate change require transformative policy responses. According to a growing public policy literature, such transformative responses typically require complex policy packages that bundle various individual policy instruments to complement each other, compensate transition losers, and create positive synergies. Nevertheless, while adding new instruments to a package can increase policy effectiveness, it comes at a price: increased policy design complexity. Increased complexity potentially leads to fundamental public misperceptions that undermine policy legitimacy and feasibility. Here, I argue that complex policy packages affect public opinion through a compensation, policy perception, and design complexity mechanism. To test this argument, this study assesses if citizens evaluate proposals for isolated climate policies related to food and mobility behaviors differently to complex policy packages. Employing a novel two-stage conjoint-experimental approach with 9115 respondents from the USA and Germany, the study shows that policy packaging increases citizens' perceived policy effectiveness to reduce climate pollutants, but also perceived restrictions on citizens' lifestyles. Moreover, increased design complexity can lead citizens to pay special attention to salient costly parts of policy packages. However, increased design complexity does not fundamentally reverse preferences. Through packaging desired and undesired policy instruments, policymakers can increase public support for transformative climate policies.
\end{abstract}

Keywords: policy design complexity; climate policy package; public opinion; political feasibility; conjoint experiment; bounded rationality; policy perception; policy effectiveness; policy intrusiveness

\section{Introduction}

Many important policy challenges, like climate change, pandemics, and digitalization, entail a high degree of complexity, both with respect to the policy problem itself and its solutions (Weber, 2017; Sewerin, 2020). In reality, effective policy solutions to 'super-wicked problems' like climate change (Levin et al., 2012, p. 124) typically require a fundamental transformation of socio-technical systems and take the form of complex policy packages - that is, a holistic combination of several policy 
instruments, rather than single policy measures (Givoni et al., 2013; Howlett and Rayner, 2013; Kivimaa and Kern, 2016; Rogge and Reichardt, 2016; Schmidt et al., 2017; Bataille et al., 2018; Markard, 2018; Kern et al., 2019). However, policymakers who propose ambitious policies for tackling climate change can face serious public opposition, given that effective instruments for accelerating system transformation can also interfere with citizens' consumption behaviors in costly ways and are perceived as restrictive (Buchanan and Tullock, 1975; Oates and Portney, 2003; Bernauer, 2013; Creutzig et al., 2018). Public backlash creates major hurdles to the adoption of transformative and behavioral climate policies given that, in democracies, the political feasibility of publicly salient policies with perceptible implications for citizens' everyday lives is - among other factors - a function of public support (Bernauer, 2013; Anderson et al., 2017; Fesenfeld, 2020; Goldberg et al., 2021; Rinscheid et al., 2021). In other words, policymakers face a trade-off between problem-solving effectiveness and political feasibility.

A growing body of literature has recently suggested that bundling costly and compensatory measures into holistic policy packages can increase public support for ambitious climate policies across different ideological groups (Häusermann et al., 2018; Ingold et al., 2019; Wicki et al., 2019, 2020; Bergquist et al., 2020; Fesenfeld et al., 2020). Nevertheless, increasing the political feasibility of ambitious climate policies by adding compensatory measures to policy packages comes at a price: increased policy design complexity. However, thus far most public opinion research has studied public support for single policy instruments, thus knowledge is lacking about the relationship between the complexity of proposed policy designs and public opinion. This paper addresses this research gap.

The study contributes to public policy, public opinion, and policy design literature by presenting an analysis of how the complexity of proposed policy designs impacts public opinion. The paper thus focuses on the contested and salient issue of climate change, which requires a rapid and fundamental transformation of socio-technical systems, for example, transport and food systems (Creutzig et al., 2018; Fesenfeld et al., 2018; Poore and Nemecek, 2018; Steg, 2018). Specifically, I experimentally assess if citizens differently evaluate isolated and combined climate policies with perceptible cost implications for citizens' day-to-day lives.

Theoretically, the study speaks to the burgeoning literature on the design of policy mixes, as well as to theories of rational choice and bounded rationality in political science and public opinion research. While classical rational choice models assume that people have stable preferences, bounded rationality theory rests on the assumption that peoples' capacity to process information in a fully rational way is restricted by cognitive limitations and resource constraints (e.g., time and knowledge) (Simon, 1957; Jones, 1999; Druckman, 2004; Jones and Baumgartner, 2005; Chong and Druckman, 2007a; Kahneman, 2011). The apparent consensus in much of the public opinion and framing literature is that people are 'cognitive misers' who seek to reduce mental effort, and that 'elites can manipulate popular preferences to serve their own interests' (Chong and Druckman, 2007a, p. 104) through '(often small) changes in the presentation of an issue or an event' (Chong and Druckman, 2007a, p. 104). By assessing how changes in the presentation and the complexity of proposed policy designs affect public opinion, this study hence also aims at contributing to the public 
choice-related debate about bounded rationality, framing, and the instability of citizens' attitudes (Converse, 1964; Achen, 1975; Page and Shapiro, 1992; Zaller, 1992; Zaller and Feldman, 1992; Jones, 1999; Freeder et al., 2019).

Going beyond the existing policy design and public opinion literature, I here argue that complex climate policy packages affect public opinion through a compensation, policy perception, and design complexity mechanism.

First, in line with classical rational choice models, the emerging public opinion literature on policy packaging often claims that policymakers need to design politically feasible policy packages in ways that compensate voters for perceived policy-induced costs (Häusermann et al., 2018; Ingold et al., 2019; Wicki et al., 2019, 2020; Bergquist et al., 2020; Fesenfeld et al., 2020; 2022). Policymakers can do this by bundling desired and undesired policy instruments into more complex policy packages (Häusermann et al., 2018; Ingold et al., 2019; Wicki et al., 2019, 2020; Bergquist et al., 2020; Fesenfeld et al., 2020).

Second, going beyond the existing literature, I hypothesize that complex policy packages also alter citizens' perceptions of policy effectiveness in reducing emissions and of policy restrictiveness (i.e., intrusiveness in personal life) (Drews and van den Bergh, 2016; Huber et al., 2019; Fesenfeld, 2020). Here, I argue that citizens perceive more complex policy package designs that combine multiple climate policy instruments as more effective at mitigating climate pollutants, but also as more restrictive than isolated climate policies.

Third, in line with bounded rationality theory (Simon, 1957), the complexity hypothesis proposed here implies that citizens have limited cognitive capacity and that their policy preferences can thus be altered by confronting voters with an increasing information load, a tactic that may be employed by politicians to avoid blame by diluting citizens' focus on policy-induced losses (Weaver, 1986; Jacobs, 2011).

To empirically examine the three potential mechanisms through which policy design complexity and packaging can affect public opinion, a two-stage, conjointbased experimental approach was designed and embedded in original surveys fielded in Germany and the USA (total $N=9115$ ), using quota sampling to ensure representative samples in terms of age, gender, income, rural-urban, and region. This conjoint design is novel since it assigns individuals to choose between randomly designed packages with varying degrees of policy design complexity, policy stringency ${ }^{1}$ (i.e., the level of ambitiousness compared to the status quo), and combinations of different policy measures. Namely, respondents in the two experimental conditions were confronted with policy proposals that included single instruments of varying stringency, or a combination of the same instruments, also of varying stringency (see Methods for details).

I selected the USA and Germany as country cases because of their importance in the global climate policy debate and their large per capita carbon footprints. Moreover, these two countries represent two mature democracies with high per capita

\footnotetext{
${ }^{1}$ Policy stringency is also termed policy intensity in other studies (Schaffrin et al., 2015). For example, a stricter emission standard or a higher carbon tax compared to the status quo would be considered a more stringent policy instrument.
} 
income but significant differences in terms of political institutions, population size, cultural norms, and individual ideological predispositions towards ambitious climate policy. Employing a survey-embedded experimental study design across these two different cases permits the comparison of results in two distinct settings and increases the external validity of findings.

In this study, I specifically focus on the case of behavioral climate policies aimed at reducing meat consumption and the use of cars that run on fossil fuels. The practical relevance of identifying politically feasible policy solutions in these two sectors is high (McCollum et al., 2018; Poore and Nemecek, 2018). At least 26\% of worldwide greenhouse gas (GHG) emissions are associated with the food sector (Poore and Nemecek, 2018), and it is the main source of global methane emissions, which increase the risk of runaway climate change in the near term (Fesenfeld et al., 2018). Without mitigating emissions from the global food system and changing diets to include more plant-based products, it will be very difficult to achieve the Paris climate targets (Clark et al., 2020). Similarly, road transport contributes more than $18 \%$ of global greenhouse gas emissions and transport-related emissions have grown steadily in recent years, constituting an important roadblock to climate change mitigation (Creutzig et al., 2015).

Moreover, I selected these two cases because effective climate policy packages in the food and transport sector typically require complex policy solutions along supply chains (Bajželj et al., 2014; Poore and Nemecek, 2018; Springmann et al., 2018). It is especially climate policies that target the behavior that can successfully trigger sociotechnical transformation to meet climate change mitigation targets which are characterized by a high level of policy design complexity, and also interfere substantially with citizens' consumption behaviors (Sparkman et al., 2021; van der Linden et al., 2020). This makes the two sectors particularly prone to public scrutiny and increases the relevance of making reliable and accurate evaluations of public opinion. Finally, comparing results across these two sectors and country cases increases the external validity of the findings.

The study proceeds as follows: First, I provide a brief review of the current policy design and packaging debate literature and identify to what extent the link between policy design complexity, packaging, and public opinion is a relevant research gap. Based on this literature review, I then develop arguments involving why and how policy packaging affects public opinion via a compensation, perception, and design complexity mechanism. After outlining the study design, I discuss empirical results and potential avenues for future research.

\section{Linking the complexity of policy designs and public opinion research}

While policy proposals can be comprised of single policy instruments (also called policy measures, such as a standalone carbon tax), they are often complex arrangements of different policy goals and policy instruments that are mixed in a more (or less) systematic fashion (Howlett and Rayner, 2013). Givoni defines a policy package as 'a combination of policy measures designed to address one or more policy objectives, created in order to improve the effectiveness of the individual policy measures, and implemented while minimizing possible unintended effects, and/or facilitating interventions' legitimacy and feasibility' (Givoni et al., 2013, p. 3). 
Givoni et al. (2013) differentiate between primary and ancillary measures. Primary measures are designed to directly affect the object of the policy - for example, reducing GHG emissions by setting regulatory emission standards for producers (Givoni et al., 2013). Ancillary measures, in contrast, aim at rectifying the potentially unintended externalities of primary measures - such as the regressive cost structure of specific consumption taxes (Hsu et al., 2008; Sælen and Kallbekken, 2011; Drews and van den Bergh, 2016; Carattini et al., 2019; Fairbrother, 2019). According to Givoni et al. (2013), the mixing of primary and ancillary measures might lead to more effective and legitimate outcomes than applying unilateral interventions (see also Rogge and Reichardt, 2016; Schmidt and Sewerin, 2019).

In theory, policymakers combine different policy instruments in an effort to meet policy goals effectively and efficiently, yet in reality, they often do not adhere to policy design principles such as consistency, coherence, and congruence (Howlett and Rayner, 2013); that is, many policymakers seek to maximize political feasibility rather than aiming for ideal-type policy designs that could more effectively solve policy problems (Gunningham and Sinclair, 1999).

Flanagan et al. (2011) and Rogge and Reichardt (2016) claim that the debate about policy mix designs originally emerged in the economic policy literature in the $1960 \mathrm{~s}$ (see, e.g., Mundell, 1962) and has only more recently spread to environmental economics (see, e.g., Lehmann, 2012), transportation research (see, e.g., Givoni et al., 2013), transition and innovation studies (see, e.g., Magro and Wilson, 2013; Kivimaa and Kern, 2016), and the field of policy analysis (see, e.g., Howlett and Rayner, 2007). However, thus far this academic debate surrounding policy mix designs has mainly focused on how combining different policy instruments increases the effectiveness of policies through the creation of positive synergies between measures (Erp and Huisman, 2010; Howlett, 2011; Howlett and Rayner, 2013).

The study of the politics of policy packaging has received less attention (Howlett and Rayner, 2013; Rogge and Reichardt, 2016; Schmidt and Sewerin, 2019). An important gap in the literature on the politics of policy packaging concerns their effect on public opinion. Public opinion is an important driver of policy action, but also a constraint on the political feasibility of costly policies (Page and Shapiro, 1983; Stimson et al., 1995; Burstein, 2003; Bernauer, 2013; Anderson et al., 2017; Stokes and Warshaw, 2017), particularly when issues become publicly salient (Culpepper, 2010). Thus far, public opinion studies have primarily concentrated on analyzing citizens' preferences for single policy measures (Fesenfeld, 2020), but besides some notable exceptions (see below), they have not accounted for the reality of policy packaging.

The small number of empirical studies that have investigated the relationship between public opinion and packaging have primarily built on small- $n$, qualitative case studies in the field of transportation policy (see, e.g., Eriksson et al., 2008; Sørensen et al., 2014). A small- $n$ experimental study by Milkman et al. (2012) suggests that packaging could be an effective strategy for overcoming the loss aversion of individuals. Some more recent studies also examined the effects of policy packaging on public opinion in the field of pension, energy, transport, and food policies with larger survey samples (Häusermann et al., 2018; Ingold et al., 2019; Wicki et al., 2019, 2020; Bergquist et al., 2020; Fesenfeld et al., 2020). However, these studies have 
not yet tested to what extent policy design complexity affects public opinion; that is, these studies did not directly compare the stability of individuals' policy perceptions and preferences for packages in contrast to single policies.

\section{Policy packaging affects public opinion through altering policy perceptions, compensation, and complexity}

The emerging public opinion literature on policy packaging has primarily focused on the compensation mechanism to explain changes in public support. In the following, I extend this line of reasoning and outline why we should not only expect public opinion to change as a result of a compensation mechanism, but also a perception and design complexity mechanism.

\section{Compensation mechanism}

Based on the assumption that voters form their policy preferences in line with their perceptions of policy-induced costs and benefits, recent research has shown that policymakers can change public support for policy proposals by combining measures that voters perceive as beneficial with measures they perceive as costly (Häusermann et al., 2018; Jagers et al., 2019; Wicki et al., 2019, 2020; Bergquist et al., 2020; Fesenfeld et al., 2020). This argument builds on a classical rational choice and utility maximization logic and assumes that voters consciously reason about their policy choices (Downs, 1957; Becker, 1976; Popkin, 1994). From this perspective, a policy's utility - that is, voters' perception of the net sum of policy-induced costs and benefits - depends on the type of policy instrument (Drews and van den Bergh, 2016; Stadelmann-Steffen and Dermont, 2018) and its level of stringency (Schaffrin et al., 2015; Pahle et al., 2018). For example, citizens tend to perceive pushbased measures like high environmental taxes as more costly and less effective than pull-based measures, such as subsidies for environmentally friendly alternatives (Drews and van den Bergh, 2016; Stadelmann-Steffen and Dermont, 2018; Huber et al., 2019; Wicki et al., 2019). Moreover, while stringent measures are usually effective at achieving environmental goals (Carley and Miller, 2012; Rhodes et al., 2014), greater stringency can also reduce public support by increasing the perceived policy-induced (behavioral and monetary) cost, particularly when targeting consumers directly, rather than producers (Creutzig et al., 2018; Fesenfeld et al., 2020).

Most recent literature explains policy packaging effects on public opinion by referring to a compensation mechanism. Consequently, public support is believed to depend on the combination of policy measures. Policymakers can increase support if packages that include instruments perceived by citizens as costly simultaneously contain instruments perceived as beneficial. In essence, packaging can help to 'pay off opponents for accepting undesired elements of a package (Cox and McCubbins, 2005; Knox-Hayes, 2012; Milkman et al., 2012; Jacobs, 2016, 2011; Häusermann et al., 2018). Accordingly, I hypothesize the following:

H1: Public support for packages including climate policy instruments that induce costs for citizens is higher if these packages simultaneously include instruments that induce benefits. 


\section{Perception mechanism}

In addition to the compensation mechanism, I here propose an additional mechanism through which policy packaging can affect public opinion: altered policy perceptions. The environmental policy design literature has highlighted the importance of citizens' perceptions of policy effectiveness and restrictiveness (i.e., perceived intrusiveness in citizens' personal lives) to explain public support for different isolated climate policy proposals. Climate policy with higher perceived effectiveness to mitigate climate change is argued to increase public support (Krosnick et al., 2006; Drews and van den Bergh, 2016; Huber et al., 2019), particularly for citizens that favor climate action (Bechtel and Scheve, 2013). In contrast, lower perceived effectiveness tends to decrease public support for climate policies (Bord et al., 2000; Steg et al., 2006; Drews and van den Bergh, 2016; Baranzini and Carattini, 2017; Stadelmann-Steffen and Dermont, 2018; Maestre-Andrés et al., 2019; Levi, 2021). Moreover, Bostrom et al. (2012) and Stadelmann-Steffen and Dermont (2018) show that people often have misperceptions about the effectiveness of policies and use these (mis-)perceptions to justify their (non) support for specific climate policies.

Similarly, the degree of a policy's restrictiveness or level of intrusiveness in citizens' personal lives is an important predictor of public support (Cherry et al., 2012; Huber et al., 2019; Wicki et al., 2019; Fesenfeld et al., 2020). More restrictive or coercive policies are generally perceived as more costly for individuals (ego-tropic concern) and other members of society (socio-tropic concern). They thus receive less support than policies that are perceived to be less restrictive (Cherry et al., 2012; Huber et al., 2019; Wicki et al., 2019; Fesenfeld et al., 2020). Generally, more stringent policy instruments are also perceived to be more restrictive, but often also more effective at mitigating climate change (Cherry et al., 2012; Huber et al., 2019; Wicki et al., 2019; Fesenfeld et al., 2020). The existing literature, however, has not yet studied the effects of policy packaging on policy perceptions.

Here, I put forward that combining multiple policies into packages can alter perceptions of policy effectiveness and restrictiveness because individuals evaluate policy proposals in comparison to other policy options (i.e., change their frame of reference). On the one hand, I argue that adding more policy instruments to a package leads individuals to perceive a proposal as more effective because of a simple 'more is better' heuristic. The premise here is that individuals think that multiple policy measures address different elements of the climate issue, create positive synergies, and are thus in combination more effective than in isolation at reducing climate pollutants. On the other hand, I argue that adding policy instruments to a package also leads people to perceive policy proposals as more restrictive, because each policy instrument added to a package is perceived to restrict citizens' personal lives to some degree.

Accordingly, I hypothesize the following:

H2a: On average, citizens perceive climate policy packages including different instruments as more effective than proposals for the same instruments made in isolation.

H2b: On average, citizens perceive proposed climate policy packages including different instruments as more restrictive than proposals for the same instruments made in isolation. 


\section{Complexity mechanism}

In addition to the perception and compensation mechanisms, I here argue that the complexity of proposed policy designs per se can also affect public opinion. This argument is in line with bounded rationality theory (Simon, 1957; Green and Shapiro, 1996; Jones, 1999; Kahneman, 2003) and political communication research which has highlighted the importance of heuristics in complex decision situations (Zaller, 1992; Druckman, 2004; Chong and Druckman, 2007a).

Increased information complexity is a key process through which proposed policy designs could affect public opinion. Per definition, increasing policy design complexity implies that new policy instruments added to a policy package simultaneously increase the cognitive burden on individuals and can lead to information satisficing (Krosnick, 1999; Bansak et al., 2018, 2019). Generally, humans tend to be able to process a maximum of nine pieces of information at a time (Miller, 1994). In information-rich situations, individuals often engage in more unconscious decision-making processes (Wason and Evans, 1974; Petty and Cacioppo, 1986; Chaiken and Trope, 1999; Kahneman, 2003). In line with bounded rationality theory (Simon, 1957), information satisficing occurs when respondents are faced with an amount of information that they cannot fully process, and hence use cognitive heuristics (Slovic, 1995; Kahneman, 2003; Lichtenstein and Slovic, 2006) to simplify decision-making and cope with this information complexity (Krosnick, 1999; Bansak et al., 2019; Jenke et al., 2021).

For example, the tax instrument may serve as a decision heuristic for respondents in complex choice situations. Depending on individuals' ideological points of view, including a tax instrument into a policy package might lead to automatic opposition or support of the package. In these situations, the support effects on the proposed package of the other included instruments would become relatively smaller. Because individuals hold different ideological priors, citizens are likely to use different instrument types (not only taxes) as their decision heuristics in complex situations. Yet, according to prospect theory (Kahneman and Tversky, 1979; Tversky and Kahneman, 1992), loss aversion predicts that citizens focus more on costs than on equivalent benefits. Arguably, costly and restrictive instruments, such as taxes and consumer restrictions, are hence politically more controversial and salient. Thus, one can expect that on average such costly and more controversial instruments serve more often as decision heuristics in complex decision situations compared to the less controversial instruments.

Overall, I thus argue that the policy design complexity mechanism affects the evaluation of individual policy instruments included in complex packages because citizens' focus of attention is altered when forming their policy preferences. Accordingly, I hypothesize the following:

H3a: The public support effects of policy instruments proposed as part of complex policy packages are smaller than the support effects of the same instruments proposed in isolation.

H3b: This effect difference is larger for those instruments that citizens perceive as less costly. 


\section{Methods}

To examine the effects of policy design complexity and packaging on public opinion, I designed conjoint choice experiments in two democratic countries. The experiments were embedded in quota-based, representative, and non-probability online public opinion surveys in Germany and the USA $(N=9115$; see details in Supplementary Material, pp. 3 and 4, Supplementary Tables 1 and 2). The survey was conducted through Lightspeed Research (Kantar TNS group), a leading company for online surveys. A matching algorithm was applied to these panels to obtain (non-probability based) samples that are representative for core sociodemographic variables (age, gender, income) of the population of eligible voters aged 18 years or older in Germany and the USA. In a choice-based conjoint experiment, individuals are given the choice between two different proposals with a number of attributes; in this case, different policy instruments (Hainmueller et al., 2014). This allows the researcher to nonparametrically estimate the average marginal component effect (AMCE); that is, the estimated marginal effect of a discretely valued attribute averaged over the joint distribution of the remaining attributes (Hainmueller et al., 2014). Given the randomization and the resulting orthogonality of each attribute with respect to every other one, the estimation of treatment effects is straightforward. In this study, the AMCE thus denotes the average marginal effect on perceptions of and support for a policy proposal when specific policy instruments are included in a package.

Choice-based conjoint experiments are particularly useful for studying the causal effects of multiple variables in complex decision-making processes and, given the realistic trade-off situation between choice options, generate higher external and ecological validity than simple stated-preference measures (Hainmueller et al., 2015; Bansak et al., 2016). I employed a conjoint-based experiment that assigned individuals to evaluate and choose between randomly designed packages with varying degrees of policy design complexity (i.e., varying numbers of policy instruments were included in the packages - see study design in Figure 2). Previous studies have not directly compared choices across different levels of policy design complexity (Häusermann et al., 2018; Jagers et al., 2019; Wicki et al., 2019; Fesenfeld et al., 2020). ${ }^{2}$

The survey experiment was structured as follows: Before citizens evaluated two randomly designed policy proposals side-by-side, I briefly described the different climate policy proposals intended to reduce meat consumption or the use of cars that run on fossil fuels (see detailed policy description texts in Supplementary Material, pp. 28ff.). Based on a review of the literature (Bajželj et al., 2014; Poore and Nemecek, 2018; Springmann et al., 2018), and six explorative expert interviews (see details in Supplementary Material, p. 32), I selected four policy instruments that respondents evaluated one after the other. The four policy measures correspond to classical policy types, that is, market- versus regulatory-based, and push versus pull measures (Howlett, 2011). The four policy measures are: (1) government financial support for low-emission products in the food and transport sector; (2) emission

\footnotetext{
${ }^{2}$ Please turn to the Supplementary Material (pp. 33ff.) for a brief note about information satisficing, masking, and the stability of average marginal component effects in conjoint analyses (Bansak et al., 2019, also see 2018; Jenke et al., 2021).
} 
standards and environmental regulations for meat and car producers; (3) taxes on meat and fossil fuels; and (4) restrictions for public cafeterias concerning which days they may offer meat, and banning cars that run on fossil fuels from city centers on specific days of the week. All four policy measures vary in terms of levels of policy stringency [i.e., the increase in policy ambitiousness compared to the status quo (Pahle et al., 2018): no change to the status quo, a medium level of policy stringency, or a high level of stringency], and in line with previous research (Stadelmann-Steffen and Dermont, 2018; Huber et al., 2019; Ingold et al., 2019; Fesenfeld et al, 2020) which are likely to be perceived as either costly or beneficial by respondents (see more details in Figure 1). Furthermore, the policy goals and the corresponding policy instruments were randomly varied between reducing the use of cars that run on fossil fuels and reducing meat consumption. The obvious condition during the randomization process was that policy instruments related to the food case (transport case, resp.) were only shown when the policy goal was randomly selected to be the reduction of meat consumption (car use, resp.).

To test how much individuals' policy perceptions and preferences vary as a function of the level of policy design complexity, I created a two-stage randomization design.

At the first stage (see Figure 2 for details), I presented each study participant ( $N=4228$ in Germany; $N=4876$ in the USA) with four pairs of randomly designed policy proposals of low complexity (i.e., without packaging different instruments together). These low-complexity proposals consisted of two attributes, namely a policy goal and one of the four individual policy instruments. The different policy instruments were described to respondents prior to the four choice tasks (see details in Supplementary Material, pp. 29ff.). Respondents were asked to decide which proposal they preferred within each pair. Besides this forced-choice question, all respondents also rated their support for each proposal on a seven-point Likert scale. In addition, individuals rated the perceived effectiveness at reducing climate pollutants of each policy proposal, as well as perceived policy restrictiveness on a seven-point Likert scale.

In the second stage (see Figure 3 for details), a sub-sample of randomly selected respondents ( $N=1409$ in Germany; $N=1624$ in the USA) was assigned to a highcomplexity conjoint task with five conjoint attributes, including a policy goal and packaging all of the four policy instruments. Again, the design of the pairs of policy packages was varied randomly. Respondents received four pairs of such randomly sorted policy packages and were asked to choose one of the two proposals within each pair in a forced-choice question, and also to rate their support and policy perceptions of each proposal on a seven-point Likert scale.

Both the full sample $(N=9115)$ for the first stage and the sub-sample of randomly selected respondents for the second stage are representative of the voting age populations in both countries (see details in Supplementary Material, pp. 3and 4, Supplementary Tables 1 and 2). The units of analysis were randomly designed policy proposals, and the primary issue of interest was the effect of policy packaging on policy perceptions and public support for these proposals in the two design stages:

First, to test H1, I investigated the AMCEs of including a specific policy instrument into a package on support for a policy proposal. Following the standard 


\begin{tabular}{|c|c|}
\hline Attribute (Instrument) & Attribute level (Varying degree of policy stringency) \\
\hline 1. Policy goal: & $\begin{array}{l}\text { 1. Reduce meat consumption to protect the climate. } \\
\text { 2. Reduce the use of cars that run on fossil fuels to protect the climate }\end{array}$ \\
\hline $\begin{array}{l}\text { 2. Government } \\
\text { financial } \\
\text { support for low- } \\
\text { emission } \\
\text { products }\end{array}$ & $\begin{array}{l}\text { 1. No increased support for low-emission food } \\
\text { 2. Support for low-emission food ( } 15 \% \text { lower prices) } \\
\text { 3. High support for low-emission food ( } 30 \% \text { lower prices) } \\
\text { 4. No increased support for low-emission means of transport } \\
\text { 5. Support for low-emission means of transport ( } 15 \% \text { lower prices) } \\
\text { 6. High support for low-emission means of transport ( } 30 \% \text { lower prices) }\end{array}$ \\
\hline $\begin{array}{l}\text { 3. Emission } \\
\text { standards and } \\
\text { environmental } \\
\text { regulations for } \\
\text { meat and car } \\
\text { producers }\end{array}$ & $\begin{array}{l}\text { 1. No increased standards for meat producers } \\
\text { 2. Standards for meat producers ( } 15 \% \text { less emissions) } \\
\text { 3. High standards for meat producers ( } 30 \% \text { less emissions) } \\
\text { 4. No increased standards for car producers } \\
\text { 5. Standards for car producers ( } 15 \% \text { less emissions) } \\
\text { 6. High standards for car producers ( } 30 \% \text { less emissions) }\end{array}$ \\
\hline $\begin{array}{l}\text { 4. Taxes on meat } \\
\text { and fossil fuels }\end{array}$ & $\begin{array}{l}\text { 1. No increased taxes on meat } \\
\text { 2. Tax on meat ( } 15 \% \text { higher prices) } \\
\text { 3. High tax on meat ( } 30 \% \text { higher prices) } \\
\text { 4. No increased taxes on fossil fuels } \\
\text { 5. Tax on fossil fuels ( } 15 \% \text { higher prices) } \\
\text { 6. High tax on fossil fuels ( } 30 \% \text { higher prices) }\end{array}$ \\
\hline 5. Restrictions & $\begin{array}{l}\text { 1. No increased limits for public cafeterias } \\
\text { 2. Limits ( } 1 \text { meat-free day/week in public cafeterias) } \\
\text { 3. High limits ( } 3 \text { meat-free days/week in public cafeterias) } \\
\text { 4. No increased limits for using cars that run on fossil fuels from city } \\
\text { centers } \\
\text { 5. Limits ( } 1 \text { day/week ban on cars that run on fossil fuels from city } \\
\text { centers) } \\
\text { 6. High limits ( } 3 \text { days/week ban on cars that run on fossil fuels from city } \\
\text { centers) }\end{array}$ \\
\hline
\end{tabular}

Figure 1. Conjoint Experimental Attribute Features. I expect the green-shaded instruments to have a positive effect on public support and compensate for the negative effects on public support of the redshaded instruments. A majority of citizens are likely to perceive the green-shaded instruments as materially or immaterially beneficial (desired), while the red-shaded instruments as materially or immaterially costly (undesired) (see more in Stadelmann-Steffen and Dermont, 2018; Huber et al., 2019; Ingold et al., 2019; Fesenfeld et al, 2020). The expectation is that the higher stringency of green-shaded instruments will increase perceived policy benefits and hence public support, while the higher stringency of redshaded instruments will increase perceived policy costs and hence decrease public support.

nonparametric estimation approach proposed by Hainmueller et al. (2014), the AMCEs were estimated by least-squares regressions, wherein the proposal attributes were entered as a series of dummy variables. Standard errors were clustered by respondents to account for autocorrelation (Hainmueller et al., 2014).

Second, to test $\mathrm{H} 2 \mathrm{a} / \mathrm{H} 2 \mathrm{~b}$, I estimated the average marginal effects of proposing a policy package compared to an isolated policy on respondents' perceived policy effectiveness and restrictiveness. To do this, I used least squares regressions with clustered standard errors to regress the policy effectiveness and restrictiveness ratings on the variable that indicated if the respective policy proposal was made in isolation (i.e., 
A. Stage I: Every respondent completes four low complexity conjoint tasks incl. two attributes

\begin{tabular}{|l|}
\hline Low complexity task (2 Attributes) \\
\hline Policy goal (reduction of meat consumption/reduction of car use) \\
+ Tax (high, medium, no change) or \\
+ Producer regulation (high, medium, no change) or \\
+ Financial support (high, medium, no change) or \\
+ Restriction (high, medium, no change)
\end{tabular}

\begin{tabular}{|l|c|c|}
\hline & Policy Package A & Policy Package B \\
\hline Policy goal: & $\begin{array}{c}\text { Reduce meat consumption to protect } \\
\text { the climate }\end{array}$ & $\begin{array}{c}\text { Reduce the use of cars that run on fossil } \\
\text { fuels to protect the climate }\end{array}$ \\
\hline Governmental support & $\begin{array}{c}\text { No increased support for low-emission } \\
\text { food }\end{array}$ & $\begin{array}{c}\text { High support for low-emission means } \\
\text { of transport (30\% lower prices) }\end{array}$ \\
\hline
\end{tabular}

Which policy package do you prefer?

B. Example of low complexity conjoint task in experimental Stage I

Policy Package A

Policy Package B

How much do you personally support policy package $\mathbf{A}$ ?

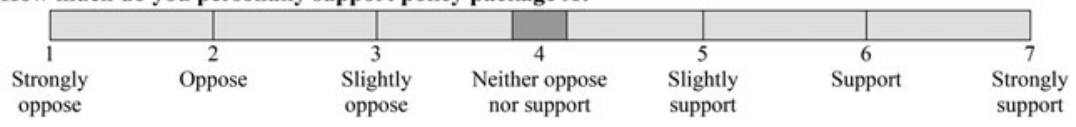

How much do you personally support policy package B?

\begin{tabular}{|c|c|c|c|c|c|c|}
\hline & & & & & & \\
\hline 1 \\
$\begin{array}{c}\text { Strongly } \\
\text { oppose }\end{array}$ & $\begin{array}{l}2 \\
\text { Oppose }\end{array}$ & $\begin{array}{c}\text { Slightly } \\
\text { oppose }\end{array}$ & $\begin{array}{c}\text { Neither oppose } \\
\text { nor support }\end{array}$ & $\begin{array}{c}\text { Slightly } \\
\text { support }\end{array}$ & Support & $\begin{array}{c}\text { Strongly } \\
\text { support }\end{array}$
\end{tabular}

Figure 2. Experimental Study Design - Stage I: In addition to the outcome choice and support ratings, respondents expressed their (dis-)agreement with the two statements for each of the two packages on a seven-point Likert scale [from 'Strongly disagree' (1) to 'Strongly agree' (7)]: Statement 1: 'Policy-package A/B is effective at protecting the climate'; Statement 2: 'Policy-package A is restrictive in terms of my lifestyle.'

stage 1 , low-complexity condition) or in combination (i.e., stage 2 , high-complexity condition). Given the fact that exactly the same policy instruments were assessed during the two experimental stages, this approach allowed me to identify the effect of packaging on policy perceptions independent of policy attribute levels.

Third, to test $\mathrm{H} 3 \mathrm{a} / \mathrm{H} 3 \mathrm{~b}$, I identified the change between estimated AMCEs for specific policy instruments as a function of the number of policy instruments included in a package. In other words, I studied if the size and direction of the AMCEs for a specific policy instrument differed if assessed in isolation (i.e., stage 1) or in combination with other policy instruments (i.e., stage 2).

Even if not essential for testing the theoretical arguments made in this paper, for increasing the policy relevance I have included in the appendix (Supplementary Material, pp. 19ff., Supplementary Figures 1-8) additional interaction analyses that show how the two policy goals and the different policy instruments potentially interact. 
A. Stage II: Random sub-sample completes four high complexity conjoint tasks incl. five attributes

\begin{tabular}{|l|}
\hline High complexity task (5 Attributes) \\
\hline Policy goal + Tax + Producer regulation + Financial support + Restriction \\
\hline
\end{tabular}

B. Example of high complexity conjoint task in experimental Stage II

\begin{tabular}{|l|c|c|}
\hline & Policy Package A & Policy Package B \\
\hline Policy goal: & $\begin{array}{c}\text { Reduce meat consumption to protect } \\
\text { the climate }\end{array}$ & $\begin{array}{c}\text { Reduce the use of cars that run on fossil } \\
\text { fuels to protect the climate }\end{array}$ \\
\hline Governmental support & $\begin{array}{c}\text { No increased support for low-emission } \\
\text { food }\end{array}$ & $\begin{array}{c}\text { High support for low-emission means } \\
\text { of transport (30\% lower prices) }\end{array}$ \\
\hline Emission standards & $\begin{array}{c}\text { High standards for meat producers } \\
(30 \% \text { less emissions) }\end{array}$ & $\begin{array}{c}\text { No increased standards for car } \\
\text { producers }\end{array}$ \\
\hline Taxes & Tax on meat (15\% higher prices) & $\begin{array}{c}\text { High tax on fossil fuels (30\% higher } \\
\text { prices) }\end{array}$ \\
\hline Restrictions & $\begin{array}{c}\text { High limits (3 meat-free days/week in } \\
\text { public cafeterias) }\end{array}$ & $\begin{array}{c}\text { Limits (1 day/week ban cars that run on } \\
\text { fossil fuels from city centers) }\end{array}$ \\
\hline
\end{tabular}

Which policy package do you prefer?

$$
\text { Policy Package A }
$$

Policy Package B

How much do you personally support policy package $\mathbf{A}$ ?

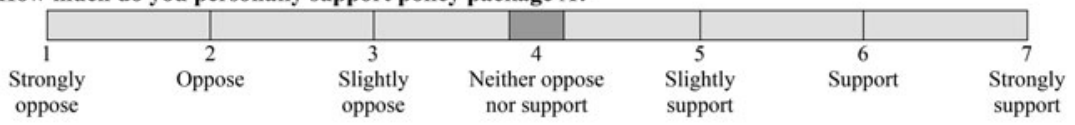

How much do you personally support policy package B?

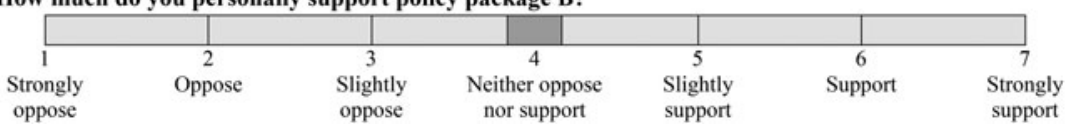

Figure 3. Experimental Study Design - Stage II: In addition to the outcome choice and support ratings, respondents expressed their (dis-)agreement with the two statements for each of the two packages on a seven-point Likert scale [from 'Strongly disagree' (1) to 'Strongly agree' (7)]: Statement 1: 'Policy-package $A / B$ is effective at protecting the climate'; Statement 2: 'Policy-package A is restrictive in terms of my lifestyle.'

\section{Results}

In the following, I first buttress existing arguments that packaging affects public support via a compensation mechanism (H1). In the next step, I present original evidence about the two novel arguments made in this study that packaging affects policy perceptions $(\mathrm{H} 2 \mathrm{a} / \mathrm{H} 2 \mathrm{~b})$ and can alter preferences via an increase in policy design complexity $(\mathrm{H} 3 \mathrm{a} / \mathrm{H} 3 \mathrm{~b})$.

\section{Policy packaging affects public opinion via a compensation mechanism}

Figure 4 presents the AMCEs for the high-complexity tasks (see detailed regression results in Supplementary Material, pp. 5 and 7, Supplementary Tables 3 and 5). 
Results show that the AMCEs for some attributes are substantial in a negative direction, while others are substantial in a positive direction. For example, the estimated effect of high taxes being included in a policy package on the probability of choosing that package is significantly negative [Germany: 8.9 percentage points $(\mathrm{SE}=1.2)$ lower choice probability; USA: 18.2 percentage points $(\mathrm{SE}=1.1)$ lower choice probability], while the estimated effect for including governmental support for lowemission product alternatives is significantly positive [Germany: 14.1 percentage points $(\mathrm{SE}=1.1)$ higher choice probability; USA: 7.8 percentage points $(\mathrm{SE}=1.1)$ higher choice probability]. Furthermore, the inclusion of strong consumption restrictions reduces the choice probability for a policy package in both countries by around 5-7 percentage points $(\mathrm{SE}=1.1)$. Interestingly, the choice effects of the consumption restriction attribute are, however, not monotonic - that is, while strong restrictions slightly reduce the choice probabilities in both countries, weaker restrictions do not have a significant negative effect. The presence of high producer standards increases choice probability in Germany by 9.4 percentage points $(\mathrm{SE}=1.2)$ and in the USA by 4.5 percentage points $(\mathrm{SE}=1.1)$. In line with the literature, the results thus buttress the first hypothesis (H1) that public support for proposed policy packages including undesired climate policy instruments is higher if these packages simultaneously include desired instruments.

The first hypothesis receives further support when taking a closer look at predicted choice probabilities (see Supplementary Material, p. 27, Supplementary Figure 9). The predicted choice probabilities of policy packages clearly depend on the exact combination of instruments included in the package. Both for Germany and the USA, we can identify a wide range of choice probabilities for differently designed policy packages that include a specific policy instrument (see Supplementary Figure 9). For example, in Germany, a package that includes a high tax on fossil fuels is chosen by $59 \%$ of respondents if the package also includes strong support for low-emission modes of transportation, a strong increase in emission standards for car producers, and no limits on accessing city centers with fossil-fueled cars. On the other hand, a package that includes a high tax on fossil fuels but no compensatory measures only receives $30 \%$ support.

\section{Policy packaging affects public opinion via a perception mechanism}

The second set of hypotheses postulate that, on average, citizens perceive proposed climate policy packages including different instruments as more effective (H2a) and restrictive $(\mathrm{H} 2 \mathrm{~b})$ than proposals for the same instruments made in isolation. The results presented in Figure 5 support this expectation (see regression results in Supplementary Tables 15-18). The findings show that both in Germany and the USA, respondents rate policy package proposals as significantly more restrictive (in Germany by 0.13 points; in the USA by 0.16 points on a seven-point Likert scale) and more effective (in Germany by 0.12 points; in the USA by 0.08 points on a sevenpoint Likert scale) than isolated policy proposals (baseline). All effects, except the effect on perceived effectiveness in the USA, are significant at the $95 \%$ confidence level. The results thus show that whether policies are presented in isolation or in combination can significantly alter respondents' policy perceptions. These findings are 


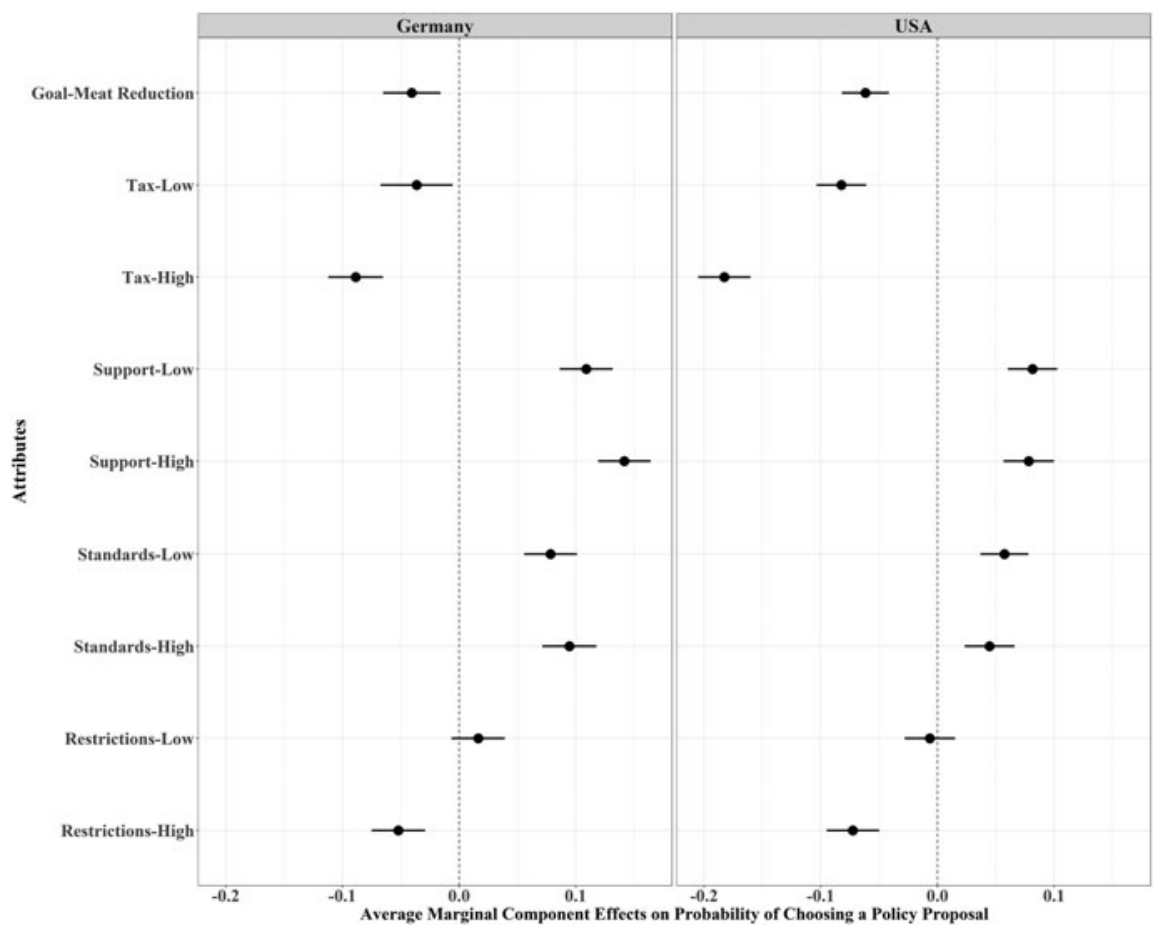

Figure 4. Estimated AMCEs of policy instruments (in high-complexity task) on the probability of choosing a package. The zero line denotes the baseline category of 'No change to the status quo.' For the policy goal, the reference category is 'Reduction of cars that run on fossil fuels.' Standard errors are clustered by respondents. The figure depicts $95 \%$ confidence intervals.

also supported by comparing AMCEs on policy perceptions in the two experimental stages (i.e., low- and high-complexity conditions). As shown in the appendix (Supplementary Material, pp. 9-16, Supplementary Tables 7-14), packaging not only affects average ratings, but also the size of AMCEs.

\section{Policy packaging affects public opinion via a complexity mechanism}

Turning to the third set of hypotheses, I first expect that public support effects of policy instruments proposed as part of complex policy packages are significantly smaller than the public support effects of the same instruments proposed in isolation (H3a).

Figure 6 presents the estimated AMCEs for when a policy instrument is evaluated in isolation (i.e., stage 1, low-complexity condition) or as part of a policy package (i.e., stage 2, high-complexity condition) (see detailed regression results in Supplementary Material, pp. 5-8, Supplementary Tables 3-6). The plot clearly shows that, on average, the size of the estimated attribute effects (AMCEs) is smaller when citizens choose policies contained in a package rather than in isolation.

For instance, a large tax increase, if evaluated in isolation (i.e., in a low-complexity condition), reduces the choice probability of a policy proposal by 15.0 percentage points in Germany ( $\mathrm{SE}=1.5$ ) and 27.2 percentage points in the USA $(\mathrm{SE}=1.3)$. In contrast, a 


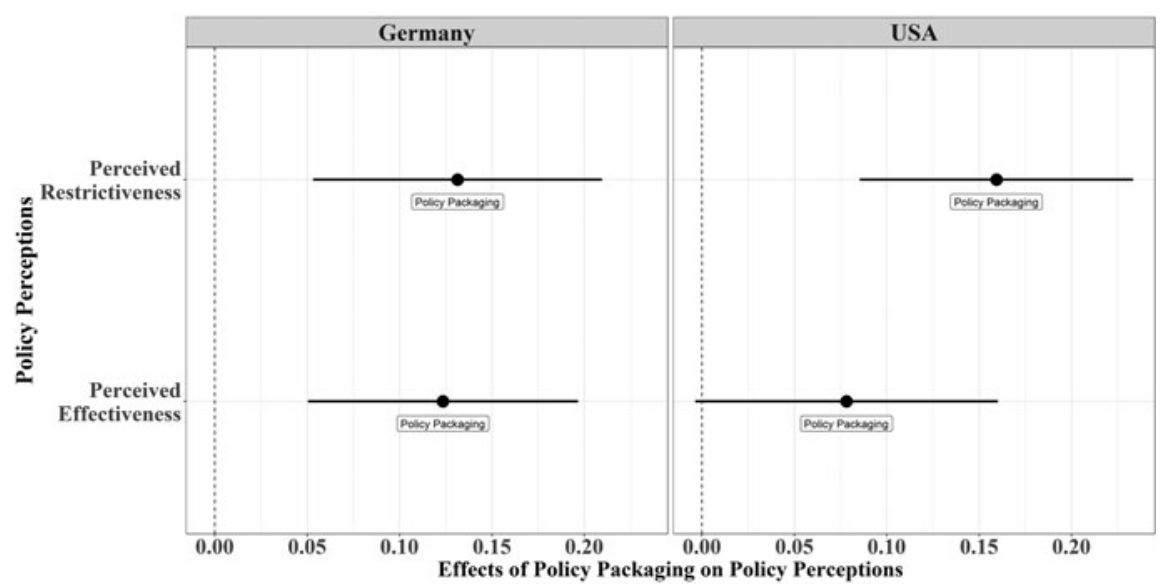

Figure 5. Estimated average marginal effects of policy packaging on respondents' perceptions of policy restrictiveness and policy effectiveness. The zero line denotes the baseline category of policies proposed in isolation (low-complexity condition). The points indicate the estimated average marginal effect of policy packaging (high-complexity condition) on the rating of perceived restrictiveness and effectiveness measured on seven-point Likert scales. Standard errors are clustered by respondents. The figure depicts 95\% confidence intervals.

large tax increase evaluated as part of a policy package (i.e., high-complexity condition) reduces the choice probability significantly less - by only 8.9 percentage points in Germany $(\mathrm{SE}=1.2)$ and 18.2 percentage points in the USA $(\mathrm{SE}=1.1)$.

Moreover, in line with hypothesis H3b, the differences in AMCEs between the high- and low-complexity conditions are smaller for instruments perceived as costly by citizens. Arguably, citizens perceive the tax and restriction instruments as personally more costly and ideologically more controversial than support for low-emission products and producer emission standards (see Figure 1). Indeed, Figure 6 shows that the difference in AMCEs between the high- and low-complexity conditions for the tax and restriction instruments is smaller than the difference in AMCEs for the other two instruments, namely the support and producer standard instruments. Thus, it is more likely that, on average, respondents focus their attention on these two instruments rather than on the less costly support and standard instruments. In other words, this finding supports the expectation grounded in prospect theory (loss aversion) that in high-complexity situations, respondents focus particularly on costly and controversial instruments as heuristics to reduce cognitive burden.

Overall, the empirical results are in line with bounded rationality theory and confirm the third set of hypotheses that public support effects of policy instruments proposed as part of complex policy packages are significantly smaller than the public support effects of the same instruments proposed in isolation.

\section{Discussion of compensation, perception, and complexity mechanisms}

Finally, I briefly discuss the key contribution of this paper - i.e., that policy packaging affects public opinion not only via a compensation mechanism but also via a perception and complexity mechanism. 


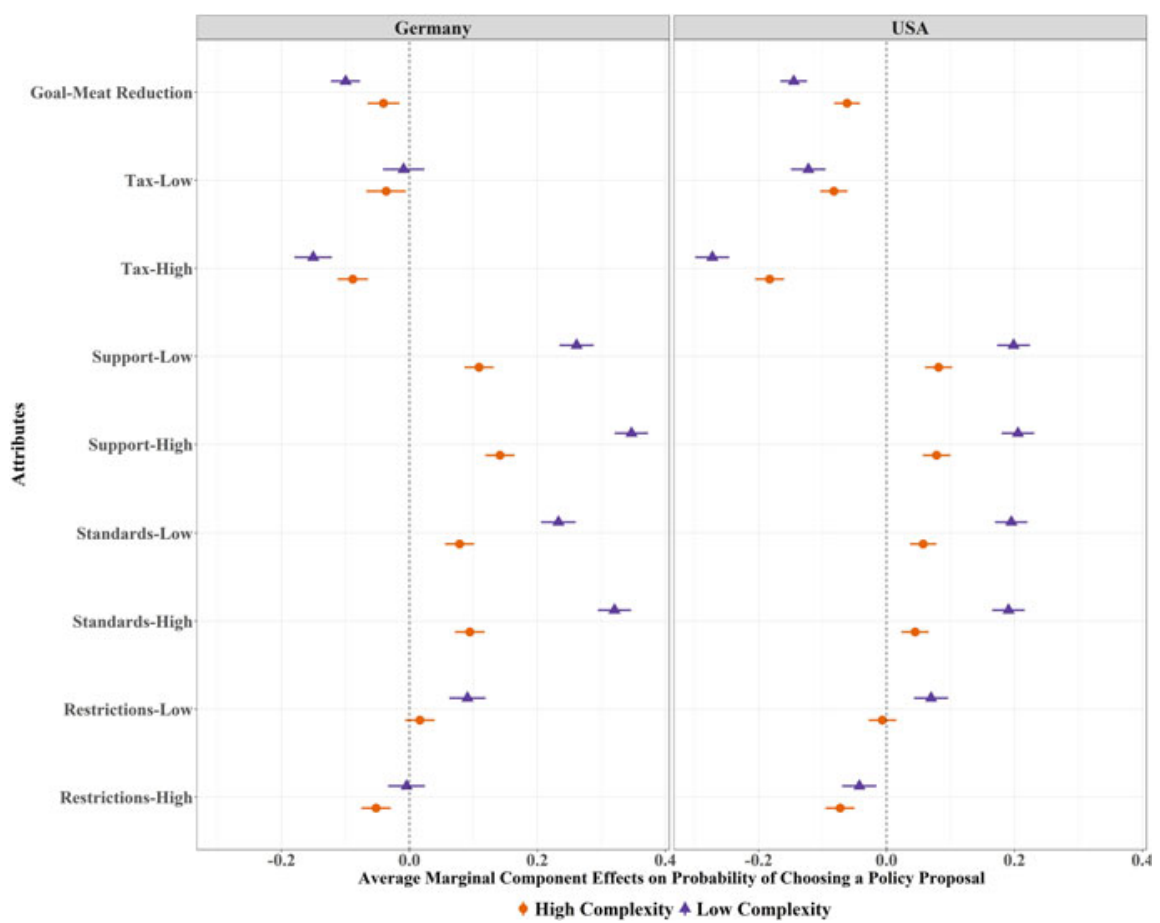

Figure 6. Estimated AMCEs of policy attributes on the choice probability for proposals in low (purple) versus high-complexity (orange) conditions. The zero line denotes the baseline category of 'No change to the status quo.' For the policy goal, the reference category is 'Reduction of cars that run on fossil fuels.' Standard errors are clustered by respondents. The figure depicts $95 \%$ confidence intervals.

First, the clear implication of the compensation mechanism is that the predicted choice probabilities of policy packages vary as a function of the combination of policy instruments that are included therein. As shown in Figure 4 (and Supplementary Figure 9), the negative effects on the public support of undesired climate policy instruments can be compensated for by combining these instruments with desired instruments. In other words, in line with the burgeoning literature on policy packaging and public opinion, I find clear evidence that compensation effects can substantially affect and increase public support for ambitious climate policies with perceptible behavioral implications.

Second, this paper provides the first empirical evidence that policy packaging also affects public opinion via a perception mechanism. As outlined in Figure 5, respondents perceive policy package proposals as significantly more effective at combatting climate change, but also as more restrictive in terms of their personal lifestyles. This finding adds to the current policy design and public opinion literature by highlighting that policy perceptions depend on proposing policies in isolation or combination (see further details in Supplementary Tables 8-18).

Third, the effect of the design complexity mechanism is that the AMCEs for different policy instruments evaluated as part of a package (i.e., in the high-complexity 
condition) are significantly smaller compared to the AMCEs for the same policies when evaluated in isolation (i.e., in a low-complexity condition). If policy design complexity did not matter, we would expect no significant differences between the AMCEs in the two complexity conditions. As illustrated in Figure 6, however, we can observe substantially different effect sizes between the two complexity conditions.

In sum, the presented findings permit the conclusion that policy packaging affects public opinion through a compensation, perception, and complexity mechanism. In this regard, an important observation, however, is that both positive and negative effects of policy instruments on public support are smaller when such policies are proposed as part of the policy package (i.e., in the high-complexity condition) rather than in isolation (i.e., in the low-complexity condition). However, especially for costly and presumably more controversial instruments, such as high taxes and consumer restrictions, the differences between the low- and high-complexity conditions are smaller than for less costly policies. Thus, in high-complexity choice situations respondents tend to use the costly parts of policy packages as decision heuristics. The increased complexity thus seems to affect less controversial instruments to a larger degree. Future research should investigate this result in more depth (see further details in Supplementary Material, pp. 34-38).

While respondents' capacity to form policy preferences can be bounded by an increase in design complexity, the higher information load does not lead citizens to fundamentally (and arguably, irrationally) reverse the overall direction of their preferences. In other words, citizens maintain their general pattern of preferences and their ability to employ a compensation logic when forming their policy attitudes. This finding is in line with the literature about the limits of framing in relation to manipulating citizens' political attitudes (Druckman, 2004, 2001; Chong and Druckman, 2007b; Bechtel et al., 2015). Especially with respect to salient and contested policy issues with perceptible implications for citizens' everyday lives, such as transformative climate policies that affect peoples' consumption habits, one may expect citizens to have more stable and consciously formed preferences (Fesenfeld et al., 2021b). Overall, the present results thus underline the crucial importance of combining costly and compensatory measures to increase support for transformative climate policies.

\section{Comparing results across countries}

Comparing the results across the two country samples shows that, taken as a whole, the results related to all three mechanisms are comparable across the two countries. In both countries, combining costly and compensatory measures leads to higher support for policy proposals (H1), packaging affects policy perceptions $(\mathrm{H} 2 \mathrm{a} / \mathrm{H} 2 \mathrm{~b})$, and AMCEs for policies integrated into packages are smaller than when policies are evaluated in isolation (H3a). In both countries, the difference in AMCEs between the high- and low-complexity conditions is also smaller for the more costly instruments (taxes and restrictions) compared to the less costly instruments $(\mathrm{H} 3 \mathrm{~b})$.

However, we also observe some interesting differences between Germany and the USA. First, while most policy instruments integrated into packages affect public support to a similar degree in both countries, in line with previous research (Klenert 
et al., 2018; Beiser-McGrath and Bernauer, 2019), high taxes have a particularly large negative support effect in the USA (minus 18.2 percentage points) compared to Germany (minus 8.9 percentage points) (see Figure 4). Second, while in Germany policy packaging increases citizens' perceived policy effectiveness and restrictiveness, in the USA packaging only increases perceived policy restrictiveness but not effectiveness (see Figure 5). This result echoes previous climate policy research that indicates the special sensibility of US citizens toward restrictions on personal liberties (Drews and van den Bergh, 2016; Dunlap et al., 2016; Harring et al., 2019; Fesenfeld, 2020). Third, generally speaking, in Germany the differences between AMCEs of policy instruments assessed in isolation (low-complexity condition) versus combination (high-complexity condition) are larger than in the USA (see Figure 6). One potential interpretation of this result is that in Germany climate policies are less polarized and AMCEs of policies evaluated in isolation are hence, on average, substantially larger than in the USA. Thus, also the differences between AMCEs in the low- and highcomplexity conditions in Germany are more likely to be larger than in the USA.

\section{Conclusion and future research}

In reality, many policy problems are complex and require transformative policy responses that take the form of holistic policy packages. Nevertheless, most public opinion research has studied public support for single policy instruments, while it remains unclear if the complexity of proposed policy designs and combining different policy instruments affects public opinion. This study uses a novel, two-stage conjoint experimental design that assigns German and US survey respondents to choose between randomly designed policy packages with varying degrees of policy design complexity and various combinations of differently stringent policy instruments. The study provides the first systematic, cross-country, and large- $n$ experimental evidence about the effects of policy design complexity and packaging on public opinion about transformative climate policies. This study thereby contributes to the burgeoning literature on policy design and public opinion about climate change specifically, and on policy preference formation more generally. While studies have thus far primarily argued that policy packaging affects public opinion via a compensation mechanism, this study proposes two additional mechanisms: a perception mechanism and a design complexity mechanism.

By comparing citizens' preferences for proposed policies evaluated in isolation and combination, the study shows that packaging affects public opinion and can increase public support for ambitious but complex climate policies that have the potential to transform socio-technical systems in line with international mitigation targets. Importantly, such packaging effects are driven not only by a compensation mechanism but also by a policy perception and complexity mechanism. While both changes in policy perceptions and increased design complexity can shift public opinion, the results also suggest that compensation is still a key mechanism for shifting public support.

While recent studies have found relatively stable AMCEs in complex conjoint experiments (Bansak et al., 2018, 2019; Jenke et al., 2021), in line with models of bounded rationality and framing theories this study shows that the level of design 
complexity can reduce support effects of instruments included in packages. This effect of smaller AMCEs in more complex decision tasks is particularly strong in respect to the less costly instruments. Thus, in more complex decision situations citizens seem to focus more on the costly and controversial design elements.

This highlights that both intuition and reasoning guide information processing, particularly in complex decision-making environments. Nevertheless, the results presented here also show that increased policy design complexity does not fundamentally reverse citizens' policy preferences.

Therefore, a key finding of this study is that policy design complexity itself is unlikely to fundamentally shift public opinion about ambitious climate policies. Facing information-rich and complex proposals for policy packages, respondents slightly adapt their policy perceptions but still apply a compensation logic when forming policy preferences. In other words, carefully combining costly and compensatory policy instruments is still crucial for increasing public support for transformative climate policies with perceptible behavioral implications for peoples' everyday lives. Given the apparent stronger focus of citizens on costly policies in more complex packages, it is however essential that policymakers particularly emphasize the beneficial design elements to compensate for the negative support effects.

More generally, this study contributes to a growing literature on the limits of framing in relation to manipulating citizens' policy attitudes and behaviors (Druckman, 2001, 2004; Chong and Druckman, 2007b; Bechtel et al., 2015; Amsalem and Zoizner, 2020; Fesenfeld, 2020). Especially with respect to salient climate policies that have perceptible effects on peoples' consumption behaviors, citizens are likely to have more stable preferences and simple framing effects might thus be limited (Bechtel et al., 2015; Fesenfeld et al., 2021a, 2021b).

One central limitation of this study is that it does not directly compare the public opinion effects of proposals for complex policy designs across issue areas with more and less perceptible cost implications for citizens' everyday lives. Future research should hence validate the findings of this study across different more or less salient issue areas, also accounting for potential logrolling effects across policy issue communities. Moreover, research could test how public opinion and interest group preferences interact with regard to such complex cross-issue 'omnibus packages.'

It would also be useful to conduct further experiments that randomly vary the number of instruments in policy packages to assess the potentially non-monotonic effects of policy design complexity. Moreover, in addition to increasing information complexity, higher policy design complexity might also shift citizens' relative reference points during the decision-making process (so-called choice bracketing effects). Future research should investigate to what extent information complexity and choice bracketing are empirically distinguishable from each other. In the appendix (see Supplementary Material, pp. 34-38), I derive hypotheses on potential choice bracketing and outline in more detail how future experiments could go beyond the limitations of this study to disentangle information complexity and choice bracketing. Such future studies could build on recent advances in combined eye-tracking and conjoint experimental methods (Jenke et al., 2021).

Moreover, further field experimental, panel, and comparative qualitative research should buttress the ecological and external validity of this study's findings. In the real 
world, journalists, politicians, and organized interest groups are likely to cherry-pick and deliberately frame the public debate around specific policy instruments, rather than address the full complexity of proposed policy packages. In such situations, the effect of policy design complexity and packaging on public opinion may differ from results obtained in the more sterile environment of a survey-embedded experiment.

Overall, the results show that there appear to be certain opportunities but also clear limits to the extent that elites can shift citizens' policy perceptions and preferences through increasing policy design complexity and obscuring policy-induced costs. In contrast to such simple communication strategies, careful policy package designs that account for compensation effects are key to increasing public support for transformative climate policies. The study calls for more cautious reflection on the standard methods for studying public opinion and policy preferences. In the real world, many policy instruments are not adopted in isolation but are part of complex policy packages. This fact should be reflected in future public opinion research across different issue areas. Accordingly, I hope the present study contributes to a fruitful debate about how policy design complexity and packaging can influence public opinion.

Supplementary material. To view supplementary material for this article, please visit https://doi.org/10. 1017/bpp.2022.3.

Acknowledgments. The author is grateful to Brile Anderson, Thomas Bernauer, Gracia Brückmann, Liam F. Beiser-McGrath, Florian Egli, Dominik Hangartner, Regula Hess, Robert Huber, Dennis Kolcava, Quynh Nguyen, David Presperger, Adrian Rinscheid, Lukas Rudolph, Nicholas Schmid, Sebastian Sewerin, Michael L. Wicki, Franziska Quoss, and Karin Ingold; to two anonymous reviewers; and to the participants of the Swiss Political Science Conference 2020 and the Swiss-German Political Methodology Conference 2019 for their support and comments.

\section{References}

Achen, C. (1975), 'Mass political attitudes and the survey response', American Political Science Review, 69: $1218-31$.

Amsalem, E. and A. Zoizner (2020), 'Real, but limited: A meta-analytic assessment of framing effects in the political domain', British Journal of Political Science 1-17. doi:10.1017/S0007123420000253.

Anderson, B., T. Böhmelt and H. Ward (2017), 'Public opinion and environmental policy output: A crossnational analysis of energy policies in Europe', Environmental Research Letters, 12: 1-10.

Bajželj, B., K. S. Richards, J. M. Allwood, P. Smith, J. S. Dennis, E. Curmi, C. a. Gilligan, W. S. Lee-gammage, B. Baj, K. S. Richards, J. M. Allwood, P. Smith, J. S. Dennis, E. Curmi and C. a. Gilligan (2014), 'Importance of food-demand management for climate mitigation', Nature Climate Change, 4: 924-9.

Bansak, K., J. Hainmueller and D. Hangartner (2016), 'How economic, humanitarian, and religious concerns shape European attitudes toward asylum seekers', Science, 354: 217-22.

Bansak, K., J. Hainmueller, D. J. Hopkins and T. Yamamoto (2018), 'The number of choice tasks and survey satisficing in conjoint experiments', Political Analysis, 26: 112-9.

Bansak, K., J. Hainmueller, D. J. Hopkins and T. Yamamoto (2019), 'Beyond the breaking point? Survey satisficing in conjoint experiments', Political Science Research and Methods 1-19. doi:10.1017/ psrm.2019.13.

Baranzini, A. and S. Carattini (2017), 'Effectiveness, earmarking and labeling: Testing the acceptability of carbon taxes with survey data', Environmental Economics and Policy Studies, 19: 197-227. doi:10.1007/ s10018-016-0144-7. 
Bataille, C., C. Guivarch, S. Hallegatte, J. Rogelj and H. Waisman (2018), 'Carbon prices across countries', Nature Climate Change, 8: 648-50.

Bechtel, M. M. and K. F. Scheve (2013), 'Mass support for global climate agreements depends on institutional design', Proceedings of the National Academy of Sciences of the United States of America, 110: 13763-8. doi:10.1073/pnas.1306374110.

Bechtel, M. M., J. Hainmueller, D. Hangartner and M. Helbling (2015), 'Reality bites: The limits of framing effects for salient and contested policy issues', Political Science Research and Methods, 3: 683-95. doi:10.1017/psrm.2014.39.

Becker, G. S. (1976), The economic approach to human behavior. Chicago: University of Chicago Press.

Beiser-McGrath, L. F. and T. Bernauer (2019), 'Could revenue recycling make effective carbon taxation politically feasible?', Science Advances, 5: eaax3323.

Bergquist, P., M. Mildenberger and L. Stokes (2020), 'Combining climate, economic, and social policy builds public support for climate action in the US', Environmental Research Letters, 15: 54019.

Bernauer, T. (2013), 'Climate change politics', Annual Review of Political Science, 16: 421-48.

Bord, R. J., R. E. O'connor and A. Fisher (2000), 'In what sense does the public need to understand global climate change?', Public Understanding of Science, 9: 205.

Bostrom, A., R. E. O’Connor, G. Böhm, D. Hanss, O. Bodi, F. Ekström, P. Halder, S. Jeschke, B. Mack and $\mathrm{M} . \mathrm{Qu}$ (2012), 'Causal thinking and support for climate change policies: International survey findings', Global Environmental Change, 22: 210-22.

Buchanan, J. M. and G. Tullock (1975), 'Polluters' profits and political response: Direct controls versus taxes', American Economic Review, 65: 139-47.

Burstein, P. (2003), 'The impact of public opinion on public policy: A review and an agenda', Political Research Quarterly, 56: 29-40.

Carattini, S., S. Kallbekken and A. Orlov (2019), 'How to win public support for a global carbon tax', Nature, 565: 289-91.

Carley, S. and C. J. Miller (2012), 'Regulatory stringency and policy drivers: A reassessment of renewable portfolio standards', Policy Studies Journal, 40: 730-56.

Chaiken, S. and Y. Trope (1999), Dual-process theories in social psychology. New York: Guilford Press.

Cherry, T. L., S. Kallbekken and S. Kroll (2012), 'The acceptability of efficiency-enhancing environmental taxes, subsidies and regulation: An experimental investigation', Environmental Science \& Policy, 16: $90-6$.

Chong, D. and J. Druckman (2007a), 'Framing theory', Annual Review of Political Science, 10: 103-26. doi:10.1146/annurev.polisci.10.072805.103054.

Chong, D. and J. Druckman (2007b), 'Framing public opinion in competitive democracies', American Political Science Review, 101: 637-55.

Clark, M. A., N. G. G. Domingo, K. Colgan, S. K. Thakrar, D. Tilman, J. Lynch, I. L. Azevedo and J. D. Hill (2020), 'Global food system emissions could preclude achieving the $1.5^{\circ}$ and $2^{\circ} \mathrm{C}$ climate change targets', Science, 370: 705-8. doi:10.1126/science.aba7357.

Converse, P. (1964), 'The nature of belief systems in mass publics', in David Apter (ed.), Ideology and discontent, New York: Free Press, 206-61.

Cox, G. W. and M. D. McCubbins (2005), Setting the agenda: Responsible party government in the US House of Representatives. Cambridge: Cambridge University Press.

Creutzig, F., P. Jochem, O. Y. Edelenbosch, L. Mattauch, D. P. van Vuuren, D. McCollum and J. Minx (2015), 'Transport: A roadblock to climate change mitigation?', Science, 350: 911-2.

Creutzig, F., J. Roy, W. F. Lamb, I. M. L. Azevedo, W. B. D. Bruin, H. Dalkmann, O. Y. Edelenbosch, F. W. Geels, A. Grubler, C. Hepburn, E. G. Hertwich, R. Khosla, L. Mattauch, J. C. Minx, A. Ramakrishnan, N. D. Rao, J. K. Steinberger, M. Tavoni, D. Ürge-vorsatz and E. U. Weber (2018), 'Towards demand-side solutions for mitigating', Nature Climate Change, 8: 260-71.

Culpepper, P. D. (2010), Quiet politics and business power: Corporate control in Europe and Japan. Cambridge: Cambridge University Press.

Downs, A. (1957), 'An economic theory of political action in a democracy', Journal of Political Economy, 65: $135-50$.

Drews, S. and J. C. J. M. van den Bergh (2016), 'What explains public support for climate policies? A review of empirical and experimental studies', Climate Policy, 16: 855-76.

Druckman, J. (2001), 'On the limits of framing effects: Who can frame?', The Journal of Politics, 63: 1041-66. 
Druckman, J. (2004), 'Political preference formation: Competition, deliberation, and the (Ir)relevance of framing effects', American Political Science Review, 98: 671-86.

Dunlap, R. E., A. M. McCright and J. H. Yarosh (2016), 'The political divide on climate change: Partisan polarization widens in the U.S.', Environment: Science and Policy for Sustainable Development, 58: 4-23. doi:10.1080/00139157.2016.1208995.

Eriksson, L., J. Garvill and A. M. Nordlund (2008), 'Acceptability of single and combined transport policy measures: The importance of environmental and policy specific beliefs', Transportation Research Part A: Policy and Practice, 42: 1117-28.

Erp, J. V. and W. Huisman (2010), 'Smart regulation and enforcement of illegal disposal of electronic waste', Criminology \& Public Policy, 9: 579-90.

Fairbrother, M. (2019), 'When will people pay to pollute? Environmental taxes, political trust and experimental evidence from Britain', British Journal of Political Science, 46: 661-82.

Fesenfeld, L. (2020), 'The political feasibility of transformative climate policy-public opinion about transforming food and transport systems', ETH Zurich. doi:10.3929/ethz-b-000425564.

Fesenfeld, L., T. S. Schmidt and A. Schrode (2018), 'Climate policy for short- and long-lived pollutants', Nature Climate Change, 8: 933-6.

Fesenfeld, L., M. Wicki, Y. Sun and T. Bernauer (2020), 'Policy packaging can make food system transformation feasible', Nature Food, 1: 173-82.

Fesenfeld, L., Y. Sun, M. Wicki, L. Beiser-McGrath and T. Bernauer (2021a), 'Systematic review raises doubts about the effectiveness of framing in climate change communication', Research Square. doi:10.21203/rs.3.rs-445613/v1.

Fesenfeld, L., Y. Sun, M. Wicki and T. Bernauer (2021b), 'The role and limits of strategic framing for promoting sustainable consumption and policy', Global Environmental Change, 68. doi:10.1016/ j.gloenvcha.2021.102266.

Fesenfeld, L., L. Rudolph and T. Bernauer (2022), 'Policy framing, design and feedback can increase public support for costly food waste regulation', Nature Food, 562: 519. doi:10.1038/s43016-022-00460-8.

Flanagan, K., E. Uyarra and M. Laranja (2011), 'Reconceptualising the "policy mix" for innovation', Research Policy, 40: 702-13.

Freeder, S., G. S. Lenz and S. Turney (2019), "The importance of knowing "What goes with what": Reinterpreting the evidence on policy attitude stability', The Journal of Politics, 81: 274-90.

Givoni, M., J. Macmillen, D. Banister and E. Feitelson (2013), 'From policy measures to policy packages', Transport Reviews, 33: 1-20.

Goldberg, M. H., A. Gustafson, M. T. Ballew, S. A. Rosenthal and A. Leiserowitz (2021), 'Identifying the most important predictors of support for climate policy in the United States', Behavioural Public Policy, 5: 480-502.

Green, D. and I. Shapiro (1996), Pathologies of rational choice theory: A critique of applications in political science. New Haven: Yale University Press.

Gunningham, N. and D. Sinclair (1999), 'Regulatory pluralism: Designing policy mixes for environmental protection', Law Policy, 21: 49-76.

Hainmueller, J., D. Hopkins and T. Yamamoto (2014), 'Causal inference in conjoint analysis: Understanding multidimensional choices via stated preference experiments', Political Analysis, 22: 1-30.

Hainmueller, J., D. Hangartner and T. Yamamoto (2015), 'Validating vignette and conjoint survey experiments against real-world behavior', Proceedings of the National Academy of Sciences, 112: 2395-2400.

Harring, N., S. C. Jagers and S. Matti (2019), 'The significance of political culture, economic context and instrument type for climate policy support: A cross-national study', Climate Policy, 19: 636-50.

Häusermann, S., T. Kurer and D. Traber (2018), 'The politics of trade-offs: Studying the dynamics of welfare state reform with conjoint experiments', Comparative Political Studies, 52: 1059-95.

Howlett, M. (2011), Designing public policies: Principles and instruments. London: Routledge.

Howlett, M. and J. Rayner (2007), 'Design principles for policy mixes: Cohesion and coherence in 'new governance arrangements.", Policy and Society, 26: 1-18.

Howlett, M. and J. Rayner (2013), 'Patching vs packaging in policy formulation: Assessing policy portfolio design', Politics and Governance, 1: 170-82.

Hsu, S.-L., J. Walters and A. Purgas (2008), 'Pollution tax heuristics: An empirical study of willingness to pay higher gasoline taxes', Energy Policy, 36: 3612-9. 
Huber, R., M. L. Wicki and T. Bernauer (2019), 'Public support for environmental policy depends on beliefs concerning effectiveness, intrusiveness, and fairness', Environmental Politics, 29: 649-73.

Ingold, K., I. Stadelmann-Steffen and L. Kammermann (2019), 'The acceptance of instruments in instrument mix situations: Citizens' perspective on Swiss energy transition', Research Policy, 48: 103694. doi:10.1016/j.respol.2018.10.018.

Jacobs, A. M. (2011), Governing for the long term: Democracy and the politics of investment. Cambridge: Cambridge University Press.

Jacobs, A. M. (2016), 'Policy making for the long term in advanced democracies', Annual Review of Political Science, 19: 433-54.

Jagers, S. C., J. Martinsson and S. Matti (2019), 'The impact of compensatory measures on public support for carbon taxation: An experimental study in Sweden', Climate Policy, 19: 147-60. doi:10.1080/ 14693062.2018.1470963.

Jenke, L., K. Bansak, J. Hainmueller and D. Hangartner (2021), 'Decision-making in conjoint experiments', Political Analysis, 29: 75-101. doi:10.1017/pan.2020.11.

Jones, B. D. (1999), 'Bounded rationality', Annual Review of Political Science, 2: 297-321. doi:10.1016/ B978-0-08-097086-8.93012-5.

Jones, B. D. and F. R. Baumgartner (2005), The politics of attention: How government prioritizes problems. Chicago: University of Chicago Press.

Kahneman, D. (2003), 'A perspective on judgment and choice: Mapping bounded rationality', American Psychologist, 58: 697-720.

Kahneman, D. (2011), Thinking, fast and slow. New York: Macmillan.

Kahneman, D. and A. Tversky (1979), 'Prospect theory: An analysis of decision under risk', Econometrica, 47: 263-91.

Kern, F., K. S. Rogge and M. Howlett (2019), 'Policy mixes for sustainability transitions: New approaches and insights through bridging innovation and policy studies', Research Policy, 48: 103832.

Kivimaa, P. and F. Kern (2016), 'Creative destruction or mere niche support? Innovation policy mixes for sustainability transitions', Research Policy, 45: 205-17.

Klenert, D., L. Mattauch, E. Combet, O. Edenhofer, C. Hepburn, R. Rafaty and N. Stern (2018), 'Making carbon pricing work for citizens', Nature Climate Change, 8: 669-77. doi:10.1038/s41558-018-0201-2.

Knox-Hayes, J. (2012), 'Negotiating climate legislation: Policy path dependence and coalition stabilization', Regulation \& Governance, 6: 545-67.

Krosnick, J. A. (1999), 'Survey research', Annual Review of Psychology, 50: 537-67.

Krosnick, J. A., A. L. Holbrook, L. Lowe and P. S. Visser (2006), 'The origins and consequences of democratic citizens' policy agendas: A study of popular concern about global warming', Climatic Change, 77: $7-43$.

Lehmann, P. (2012), 'Justifying a policy mix for pollution control: A review of economic literature', Journal of Economic Surveys, 26: 71-97.

Levi, S. (2021), 'Why hate carbon taxes? Machine learning evidence on the roles of personal responsibility, trust, revenue recycling, and other factors across 23 European countries', Energy Research \& Social Science, 73: 101883.

Levin, K., B. Cashore, S. Bernstein and G. Auld (2012), 'Overcoming the tragedy of super wicked problems: Constraining our future selves to ameliorate global climate change', Policy Sciences, 45: 123-52.

Lichtenstein, S. and P. Slovic (2006), The construction of preference. New York: Cambridge University Press.

Maestre-Andrés, S., S. Drews and J. van den Bergh (2019), 'Perceived fairness and public acceptability of carbon pricing: A review of the literature', Climate Policy, 19: 1186-204.

Magro, E. and J. R. Wilson (2013), 'Complex innovation policy systems: Towards an evaluation mix', Research Policy, 42: 1647-56.

Markard, J. (2018), 'The next phase of the energy transition and its implications for research and policy', Nature Energy, 3: 628-33. doi:10.1038/s41560-018-0171-7.

McCollum, D., C. Wilson, M. Bevione, S. Carrara, O. Y. Edelenbosch, J. Emmerling, C. Guivarch, P. Karkatsoulis, I. Keppo and V. Krey (2018), 'Interaction of consumer preferences and climate policies in the global transition to low-carbon vehicles', Nature Energy, 3: 664.

Milkman, K. L., M. C. Mazza, L. L. Shu, C. J. Tsay and M. H. Bazerman (2012), 'Policy bundling to overcome loss aversion: A method for improving legislative outcomes', Organizational Behavior and Human Decision Processes, 117: 158-67. 
Miller, G. A. (1994), 'The magical number seven, plus or minus two: Some limits on our capacity for processing information', Psychological Review, 101: 343.

Mundell, R. A. (1962), 'The appropriate use of monetary and fiscal policy for internal and external stability', IMF Staff Paper, 9: 70-9.

Oates, W.E. and P. R. Portney (2003), 'The political economy of environmental policy', in K. Mäler and J. Vincent (eds), Handbook of environmental economics, Amsterdam: Elsevier, 325-54.

Page, B. I. and R. Y. Shapiro (1983), 'Effects of public opinion on policy', American Political Science Review, 77: 175-90.

Page, B. I. and R. Y. Shapiro (1992), The rational public: Fifty years of trends in Americans' policy preferences. Chicago: University of Chicago Press.

Pahle, M., D. Burtraw, C. Flachsland, N. Kelsey, E. Biber and J. Meckling (2018), 'Sequencing to ratchet up climate policy stringency', Nature Climate Change, 8: 861-7.

Petty, R.E. and J. T. Cacioppo (1986), Communication and persuasion. New York: Springer

Poore, J. and T. Nemecek (2018), 'Reducing food's environmental impacts through producers and consumers', Science, 360: 987-92.

Popkin, S. L. (1994), The reasoning voter: Communication and persuasion in presidential campaigns. University of Chicago Press. doi:10.2307/3791718.

Rhodes, E., J. Axsen and M. Jaccard (2014), 'Does effective climate policy require well-informed citizen support?', Global Environmental Change, 29: 92-104.

Rinscheid, A., S. Pianta and E. U. Weber (2021), 'What shapes public support for climate change mitigation policies? The role of descriptive social norms and elite cues', Behavioural Public Policy, 5: 503-527.

Rogge, K. S. and K. Reichardt (2016), 'Policy mixes for sustainability transitions: An extended concept and framework for analysis', Research Policy, 45: 1620-35.

Schaffrin, A., S. Sewerin and S. Seubert (2015), 'Toward a comparative measure of climate policy output', Policy Studies Journal, 43: 257-82.

Schmidt, T. S. and S. Sewerin (2019), 'Measuring the temporal dynamics of policy mixes - An empirical analysis of renewable energy policy mixes' balance and design features in nine countries', Research Policy, 48: 103557.

Schmidt, T. S., T. Matsuo and A. Michaelowa (2017), 'Renewable energy policy as an enabler of fossil fuel subsidy reform? Applying a socio-technical perspective to the cases of South Africa and Tunisia', Global Environmental Change, 45: 99-110. doi:10.1016/j.gloenvcha.2017.05.004.

Sewerin, S. (2020), 'Understanding complex policy mixes: Conceptual and empirical challenges', in G. Capano and M. Howlett (eds), A modern guide to public policy, Cheltenham: Edward Elgar Publishing, 191-202.

Simon, H. (1957), Models of man: Social and rational. Hoboken: Wiley.

Sælen, H. and S. Kallbekken (2011), 'A choice experiment on fuel taxation and earmarking in Norway', Ecological Economics, 70: 2181-90. doi:10.1016/j.ecolecon.2011.06.024.

Slovic, P. (1995), 'The construction of preference', American Psychologist, 50: 364.

Sørensen, C., K. Isaksson, J. Macmillen, J. Åkerman and F. Kressler (2014), 'Strategies to manage barriers in policy formation and implementation of road pricing packages', Transportation Research Part A: Policy and Practice, 60: 40-52.

Sparkman, G., L. Howe and G. Walton (2021), 'How social norms are often a barrier to addressing climate change but can be part of the solution', Behavioural Public Policy, 5: 528-555.

Springmann, M., M. Clark, D. Mason-D’Croz, K. Wiebe, B. L. Bodirsky, L. Lassaletta, W. de Vries, S. J. Vermeulen, M. Herrero and K. M. Carlson (2018), 'Options for keeping the food system within environmental limits', Nature, 562: 1.

Stadelmann-Steffen, I. and C. Dermont (2018), 'The unpopularity of incentive-based instruments: What improves the cost-benefit ratio?', Public Choice, 175: 1-26.

Steg, L. (2018), 'Limiting climate change requires research on climate action', Nature Climate Change, 8: 759-61. doi:10.1038/s41558-018-0269-8.

Steg, L., L. Dreijerink and W. Abrahamse (2006), 'Why are energy policies acceptable and effective?', Environment and Behavior, 38: 92-111. doi:10.1177/0013916505278519.

Stimson, J. A., M. B. MacKuen and R. S. Erikson (1995), 'Dynamic representation', American Political Science Review, 89: 543-65. 
Stokes, L. C. and C. Warshaw (2017), 'Renewable energy policy design and framing influence public support in the United States', Nature Energy, 2: 17107.

Tversky, A. and D. Kahneman (1992), 'Advances in prospect theory: Cumulative representation of uncertainty', Journal of Risk and Uncertainty, 5: 297-323.

van der Linden, S., A. R. Pearson and L. Van Boven (2020), 'Behavioural climate policy', Behavioural Public Policy 1-9. doi:10.1017/bpp.2020.44.

Wason, P. and J. Evans (1974), 'Dual processes in reasoning?', Cognition, 3: 141-54. doi:10.1016/0010-0277 (74)90017-1.

Weaver, R. K. (1986), 'The politics of blame avoidance', Journal of Public Policy, 6: 371-98.

Weber, E. U. (2017), 'Breaking cognitive barriers to a sustainable future', Nature Human Behaviour 1: 0013.

Wicki, M., L. P. Fesenfeld and T. Bernauer (2019), 'In search of politically feasible policy-packages for sustainable passenger transport: Insights from choice experiments in China, Germany, and the USA', Environmental Research Letters, 14: 1-17. doi:10.1088/1748-9326/ab30a2.

Wicki, M., R. Huber and T. Bernauer (2020), 'Can policy-packaging increase public support for costly policies? Insights from a choice experiment on policies against vehicle emissions', Journal of Public Policy, 4: 599-625.

Zaller, J. R. (1992), The nature and origins of mass opinion. Cambridge: Cambridge University Press.

Zaller, J. and S. Feldman (1992), 'A simple theory of the survey response: Answering questions versus revealing preferences', American Journal of Political Science, 36: 579-616.

Cite this article: Fesenfeld LP (2022). The effects of policy design complexity on public support for climate policy. Behavioural Public Policy 1-26. https://doi.org/10.1017/bpp.2022.3 